\title{
Evaluation of IL10, TGF-B and Specific IgE and IgG Levels during Sublingual Rye Grass Immunotherapy
}

Akefeh Ahmadiafshar ${ }^{1 *}$, Babak Taymourzadeh ${ }^{2}$, Ablbolkarim Shaikhi $^{3}$, Saeedeh Mazloomzadeh ${ }^{4}{\text { and } Z^{2} \text {.hre Torabi }}^{2}$

${ }^{1}$ Mousavi Hospital and Metabolic Research Center of Zanjan University of Medical Sciences, Zanjan, Iran

${ }^{2}$ Mousavi Hospital, Zanjan University of Medical Sciences, Zanjan, Iran

${ }^{3}$ Department of Immunology, Dezfool University of Medical Sciences, Dezfool, Iran

${ }^{4}$ Metabolic Research Center, Zanjan University of Medical Sciences, Zanjan, Iran

\begin{abstract}
Background: Sublingual Immunotherapy (SLIT) is a safe mechanism for treatment of some allergic disorders. This study investigated the effect of SLIT on specific IgG, IgE, Interlukin 10 (IL10) and Transforming Growth Factor beta (TGF- $\beta$ ) levels
\end{abstract}

Material and methods: This randomized double blind trial was performed 2 months prior to the grass pollination till the end of the season for about 6 months. Patients (5-18 yrs old) with allergic rhinitis to rye grass pollen, randomly received grass pollen or placebo extract and specific IgG and IgE level were assessed. IL10 and TGF- $\beta$ were also measured before and after treatment. Data were analyzed by SPSS software.

Results: Twenty of 24 patients completed the study. We did not find any significant difference in specific $\lg G$ and IgE levels before and after study between the two groups, however there was statistically significant elevation of IL10 $(P V=0.003)$ and TGF- $\beta(P V=0.006)$ levels after immunotherapy in the intervention group.

Conclusion: This study showed sublingual immunotherapy had significant effect on regulatory cytokines.

Keywords: Sublingual immunotherapy; Rye grass; Interleukin 10 (IL10); Transforming Growth Factor beta (TGF- $\beta$ ); Allergic rhinitis

\section{Introduction}

Allergen specific immunotherapy has been used in human as an effective treatment of allergic disorders [1-3]. Subcutaneous injection was known as a classic form of administration, but recently sublingual rout have been considered as an alternative method. It is now shown that Sublingual Immunotherapy (SLIT) is much safer than Subcutaneous Immunotherapy (SCIL), [2,4-7] because it is noninvasive and in several studies it was shown that it reduces both symptoms and medical requirements $[2,8-10]$. Some studies showed immunologic changes during SLIT such as increased Th1 to Th2 activities and increased T regulatory cytokine secretion [11-14], but other studies did not show significant effects [15-17]. Rye grass is the most common allergen in our area specially in children and youth and could affect activity and school works of sensitive patients [18].

In our study the effect of sublingual rye immunotherapy on specific IgE and IgG levels and IL10 and TGF B production was investigated.

\section{Material and Method}

This double blind, placebo-controlled trial was conducted in allergy clinic of Mousavi hospital in Zanjan City from March to August 2010. This Trial was registered in Iranian Registry of Clinical Trial. (IRCT No: $138812042967 \mathrm{N1}$ ) and approved by Ethic committee of Zanjan University of Medical Sciences. Thirty patients were invited to study and after obtaining a written consent, 24 subjects (5-18 years old) accepted to run into trial and randomly received sublingual immunotherapy or placebo. Patients with clinical history of significant grass pollen allergic rhinitis or rhino-conjunctivitis for 2 years or more and positive skin prick test (Stallergen France, wheal diameter $>3 \mathrm{~mm}$ ) to rye grass were included in this study. Patients who had moderate to severe asthma in accordance to GINA Guideline [19], multiple positive skin tests to other allergens and systemic or autoimmune disease were excluded from the study.
Rye grass extracts (Staloral 638, Stallergen, France) were instructed to spray under the tongue and kept about 1-3 minutes and then swallowed. Study started 8-10 weeks before grass pollen season with dose of 10 IR extract. During the build up phase, the dose was increased at alternate day. When the dose of 900 IR was achieved, it was continued 3 times a week as a maintenance therapy until the end of season. All patients were visited monthly and were in contact by phone call during study. Patients in placebo group received similar pattern of therapy. Blood sampling was done at the beginning and at the end of study. IL10 and TGF- $\beta$ were evaluated in supernatants of cultured peripheral blood mononuclear cells after isolation by ficoll-hypaque. The quantitative determination was performed by Enzyme linked immunosorbant assay. (MT EAST, Dr Hook, Germany) specific IgG and IgE to Rye grass were also measured by enzyme-linked immunosorbant assay (Dr Hook Germany). Symptoms and medical score of patients were also measured in a parallel study [20].

The Kolmogorov-Smirnov test was used to evaluate the distribution of quantitative variables. Values were expressed as mean \pm standard deviation, as appropriate. Comparisons were performed by chi-square test for categorical variables, independent or paired t-test for normally distributed, and Mann-Whitney or Wilcoxon test for non-normally distributed. $\mathrm{P}<0.05$ was considered as statistically significant.

*Corresponding author: Akefeh Ahmadiafshar, Metabolic Disease Research Center, Zanjan University of Medical Sciences, Zanjan, Iran Tel: +98-241-4131429/ +98-9122418830; Fax: 0098-241-7270751; E-mail: akefeh45@zums.ac.ir,zu_afshar@yahoo.com

Received February 15, 2013; Accepted March 16, 2013; Published March 21 2013

Citation: Ahmadiafshar A, Taymourzadeh B, Shaikhi A, Mazloomzadeh S, Torabi Z (2013) Evaluation of IL 10, TGF-B and Specific lgE and Ig G Levels during Sublingua Rye Grass Immunotherapy. J Aller Ther 4: 132. doi:10.4172/2155-6121.1000132

Copyright: () 2013 Ahmadiafshar A, et al. This is an open-access article distributed under the terms of the Creative Commons Attribution License, which permits unrestricted use, distribution, and reproduction in any medium, provided the original author and source are credited. 
Citation: Ahmadiafshar A, Taymourzadeh B, Shaikhi A, Mazloomzadeh S, Torabi Z (2013) Evaluation of IL10, TGF-B and Specific IgE and IgG Levels during Sublingual Rye Grass Immunotherapy. J Aller Ther 4: 132. doi:10.4172/2155-6121.1000132

Page 2 of 3

\section{Results}

Twenty of 24 patients (10 patients as treatment and 10 patients as placebo group) completed the study. Mean age of treatment group and placebo group was similar; $8.13 \pm 2.5$ vs. $9.14 \pm 6.4(\mathrm{p}=0.62)$. The female to male ratio were $8 / 2$ and $7 / 3$ in treatment and placebo groups respectively $(\mathrm{p}=0.61)$.

We did not find any significant changes in specific Rye grass IgG levels between treatment and placebo groups before and after immunotherapy. Specific IgE levels also were not changed statistically significant after treatment, between the two groups. At the beginning of study, IL10 and TGF $\beta$ level was greater in control group, however after immunotherapy the amount of IL10 and TGF- $\beta$ in treatment group was significantly increased whilst we found decreasing levels of both in control group after treatment. There was significantly greater amount of IL10 and TGF- $\beta$ in treatment group in comparison to placebo after 6 months of immunotherapy (Figure 1) (Tables1-4).

\section{Discussion}

In this randomized clinical trial study, sublingual immunotherapy with rye grass did not significantly change specific IgG and IgE levels after 6 months. This may be due to the short course of our study. Several studies showed significant alternations of specific IgG and IgE after I-3

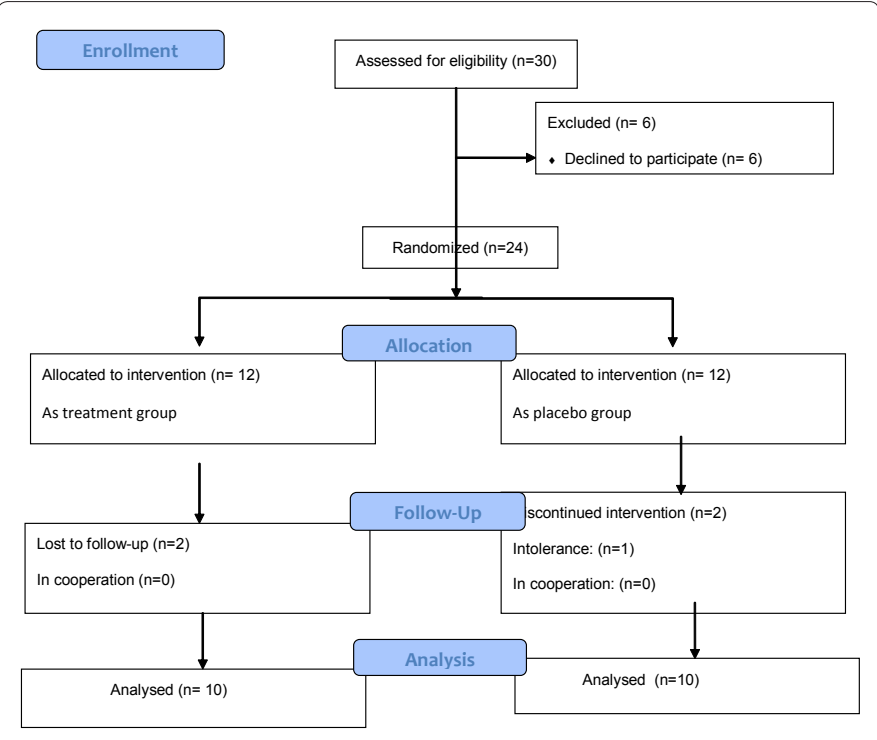

Figure 1: The Diagram of study.

\begin{tabular}{|l|l|l|l|}
\hline IgG & Immunotherapy* & Control** $^{* *}$ & P Value \\
\hline Baseline & $139 \pm 40$ & $145 \pm 16$ & 0.679 \\
\hline After months & $127 \pm 24$ & $135 \pm 42$ & 0.629 \\
\hline
\end{tabular}

${ }^{*} \mathrm{P} v$ before and after immunotherapy in treatment group $=0.479$

${ }^{* *} \mathrm{Pv}$ before and after immunotherapy in control group $=0.411$

Table 1: Mean specific $\mathrm{lgG}(\mu \mathrm{g} / \mathrm{ml})$ in the immunotherapy and placebo groups at the baseline and 6 months after treatment.

\begin{tabular}{|l|l|l|l|}
\hline IgE & Immunotherapy* $^{*}$ & Control $^{\star *}$ & P Value \\
\hline Baseline & $2.62 \pm 0.27$ & $1.26 \pm 0.23$ & 0.149 \\
\hline After 6 months & $1.41 \pm 0.61$ & $1.47 \pm 0.24$ & 0.768 \\
\hline
\end{tabular}

${ }^{*} \mathrm{P} v$ before and after immunotherapy in treatment group $=0.176$

${ }^{* *} \mathrm{Pv}$ before and after immunotherapy in control group $=0.131$

Table 2: Mean specific $\lg E(\mathrm{U} / \mathrm{ml})$ in the immunotherapy and control groups at the baseline and 6 months after treatment.

\begin{tabular}{|l|l|l|l|}
\hline IL10 & Immunotherapy* $^{*}$ & Control $^{* *}$ & P Value \\
\hline Baseline & $188.9 \pm 94.81$ & $277 \pm 121.59$ & 0.086 \\
\hline After 6 months & $314.9 \pm 96.53$ & $216 \pm 96.6$ & 0.035 \\
\hline
\end{tabular}

${ }^{*} \mathrm{Pv}$ before and after immunotherapy in treatment group $=0.003$

${ }^{* *} \mathrm{P} v$ before and after immunotherapy in control group $=0.012$

Table 3: Mean IL10 (pg/ml) amount in the immunotherapy and control groups at the baseline and 6 months after treatment.

\begin{tabular}{|l|l|l|l|}
\hline TGF- $\boldsymbol{\beta}(\mathbf{p g} / \mathbf{m l})$ & Immunotherapy* & Control** & P Value \\
\hline Baseline & $173.4 \pm 73.15$ & $284 \pm 126.4$ & 0.027 \\
\hline After 6 months & $326.4 \pm 126.7$ & $250.4 \pm 110.5$ & 0.017 \\
\hline
\end{tabular}

${ }^{*} \mathrm{P} v$ before and after immunotherapy in treatment group $=0.006$

${ }^{* *} \mathrm{P} v$ before and after immunotherapy in control group $=0.182$

Table 4: Mean TGF- $\beta$ amount in the immunotherapy and control groups at the baseline and 6 months after treatment.

years of immunotherapy [21-23]. Although Dehlink et al. did not find any significant immunologic changes during a short period of 8 weeks [16],in the study of Marcucci et al. significant changes in specific IgE and IgG4 levels in a short period of therapy were shown [24].

Assessment of total specific IgG level instead of IgG4 level could influence our results. In a similar study IgG4 levels were significantly raised after 6 months SLIT with grass pollen extracts [25]. However Mosges et al. showed that serum-specific IgG4 levels did not statistically differ in comparison to control after 9 months of SLIT in spite of significant reduction of symptom score, medical score and skin test titration [26]. We found similar results in a parallel study of our patients [20]. In study of Pfaar and Klimek allergen-specific IgE didn't change, although specific $\operatorname{IgG} 4$ and $\operatorname{IgG} 1$ increased with active treatment in the first and second study years compared with placebo [27].

One study also did not show any alternation of serum IgE/IgG4 ratios over time after 1 and 2 years SLIT [17]. Rossi et al. showed only high dose SLIT regimen results in an appreciable serum specific IgG4 increase [28]. We found increasing amount of IL10 and TGF- $\beta$ levels in immunotherapy group, whereas significant reduction was observed in placebo group in comparison with baseline level and active treatment group. It implicated the induction of regulatory T cells by SLIT. Thus, SLIT could induce a systemic immunologic response. T regulatory cells induced by immunotherapy are type 1 cells producing high levels of IL10 and TGF- $\beta$. Both cytokines decrease the release of pro-inflammatory mediators and inhibit the production of Th2 cytokines. Savolainen et al. showed high-dose SLIT, induced activation of regulatory cytokine IL10 and TGF- $\beta$ associated with inhibitory effect on IL-5 expression [29] Piconi et al. demonstrated that SLIT was associated with modulation of programmed cell death ligand 1 expression and IL-10 synthesis and favors the production of allergen-specific IgG4 [30]. In study of Ciprandi et al. there was negative relationship between TGF- $\beta$ and eosinophilia in patients after SLIT and also higher levels of IgG and IgA in SLIT-treated patients [31]

Induction of $\mathrm{T}$ regulatory cells during SLIT seems to play a central role in inhibition of allergic inflammatory responses. Type 1 $\mathrm{T}$ regulatory cells produce increasing amounts of IL-10 and TGF- $\beta$ associated with decreasing $\operatorname{IgE}$ and enhancement of $\operatorname{IgG} 4$ and $\operatorname{IgA}$ production, respectively [32]. Remarkably, this increase in IL10 was significant as early as 2-4 weeks during immunotherapy [33]. We found improvement of symptoms and medical score and also skin test reduction in patients during SLIT in our recent study [20]. Therefore, induction of T regulatory cells and production of IL-10 and TGF- $\beta$ should be important mechanism for achieving effective treatment. 
Citation: Ahmadiafshar A, Taymourzadeh B, Shaikhi A, Mazloomzadeh S, Torabi Z (2013) Evaluation of IL10, TGF-B and Specific IgE and IgG Levels during Sublingual Rye Grass Immunotherapy. J Aller Ther 4: 132. doi:10.4172/2155-6121.1000132

\section{Conclusion}

This study shows SLIT could change the immune profile of patients especially by induction of regulatory $\mathrm{T}$ cells after a short course of treatment. In addition, considering its convenience and safety administration, it is better to be recommended for treatment of children with poorly controlled allergic rhinitis.

\section{Acknowledgment}

This study is graduated thesis of Dr Babak Taymourzadeh and was supported by research council of Zanjan University of Medical Sciences. We also thank Dr Pouran Sepehrzad the representative of Stalergens Company for preparing allergic extract, Dr Parisa Khoshnevis for helping in writing of manuscript and all the patients who participated in the study.

\section{References}

1. Akdis CA, Blaser $K(2000)$ Mechanisms of allergen-specific immunotherapy. Allergy 55: 522-530.

2. Nelson HS (2003) Advances in upper airway diseases and allergen immunotherapy. J Allergy Clin Immunol 111: S793-798.

3. Bidad K, Nicknam MH, Farid R (2011) A review of allergy and allergen specific immunotherapy. Iran J Allergy Asthma Immunol 10: 1-9.

4. Passalacqua G, Garelli V, Sclifò F, Canonica GW (2013) Sublingual immunotherapy for allergic rhinitis and conjunctivitis. Immunotherapy 5: 257264

5. Bousquet $J$ (2005) Sublingual immunotherapy: from proven prevention to putative rapid relief of allergic symptoms. Allergy 60: 1-3.

6. Moingeon P, Batard T, Fadel R, Frati F, Sieber J, et al. (2006) Immune mechanisms of allergen-specific sublingual immunotherapy. Allergy 61: 151165.

7. Leatherman BD, Owen S, Parker M, Chadwick S, Fornadley JA, et al. (2007) Sublingual Immunotherapy: Past, present, paradigm for the future? A review of the literature. Otolaryngol Head Neck Surg 136: S1-20.

8. Dahl R, Kapp A, Colombo G, de Monchy JG, Rak S, et al. (2006) Efficacy and safety of sublingual immunotherapy with grass allergen tablets for seasonal allergic rhinoconjunctivitis. J Allergy Clin Immunol 118: 434-440.

9. Penagos M, Passalacqua G, Compalati E, Baena-Cagnani CE, Orozco S, et al. (2008) Metaanalysis of the efficacy of sublingual immunotherapy in the treatment of allergic asthma in pediatric patients, 3 to 18 years of age. Chest 133: 599-609.

10. Wilson DR, Lima MT, Durham SR (2005) Sublingual immunotherapy for allergic rhinitis: systematic review and meta-analysis. Allergy 60: 4-12.

11. Nieminen K, Laaksonen K, Savolainen J (2009) Three-year follow-up study of allergen-induced in vitro cytokine and signalling lymphocytic activation molecule mRNA responses in peripheral blood mononuclear cells of allergic rhinitis patients undergoing specific immunotherapy. Int Arch Allergy Immunol 150: $370-376$.

12. Gardner LM, Thien FC, Douglass JA, Rolland JM, O'Hehir RE (2004) Induction of $T$ 'regulatory' cells by standardized house dust mite immunotherapy: an increase in CD4+ CD25+ interleukin-10+ T cells expressing peripheral tissue trafficking markers. Clin Exp Allergy 34: 1209-1219.

13. Ciprandi G, Fenoglio D, Cirillo I, Vizzaccaro A, Ferrera A, et al. (2005) Induction of interleukin 10 by sublingual immunotherapy for house dust mites: a preliminary report. Ann Allergy Asthma Immunol 95: 38-44.

14. Ebner C, Siemann U, Bohle B, Willheim M, Wiedermann U, et al. (1997) Immunological changes during specific immunotherapy of grass pollen allergy: reduced lymphoproliferative responses to allergen and shift from $\mathrm{TH} 2$ to $\mathrm{TH} 1 \mathrm{in}$ T-cell clones specific for Phl p 1, a major grass pollen allergen. Clin Exp Allergy 27: $1007-1015$

15. Ciepiela O, Zawadzka-Krajewska A, Kotula I, Wasik M, Demkow U (2010) Sublingual immunotherapy in asthma does not influence lymphocyte sensitivity to Fas stimulation. Eur J Med Res 15 Suppl 2: 17-20.

16. Dehlink E, Eiwegger T, Gerstmayr M, Kampl E, Bohle B, et al. (2006) Absence of systemic immunologic changes during dose build-up phase and early maintenance period in effective specific sublingual immunotherapy in children. Clin Exp Allergy 36: 32-39.
17. Rolinck-Werninghaus C, Kopp M, Liebke C, Lange J, Wahn U, et al. (2005) Lack of detectable alterations in immune responses during sublingual immunotherapy in children with seasonal allergic rhinoconjunctivitis to grass pollen. Int Arch Allergy Immunol 136: 134-141.

18. Ahmadiafshar A, Sepehri S, Mousavinasab S, Torabi S (2008) Recognition and frequency of common allergens in allergic patients of zanian by skin prick test. Zanjan University of Medical Science J: 64.

19. (2007) Guidelines for the diagnosis and management of asthma. Department of Health and Human Services., National Heart Lung and Blood Institute.

20. Ahmadiafshar A, Maarefvand M, Taymourzade B, Mazloomzadeh S, Torabi Z (2012) Efficacy of sublingual swallow immunotherapy in children with rye grass pollen allergic rhinitis: a double-blind placebo-controlled study. Iran J Allergy Asthma Immunol 11: 175-181.

21. Bufe A, Ziegler-Kirbach E, Stoeckmann E, Heidemann P, Gehlhar K, et al (2004) Efficacy of sublingual swallow immunotherapy in children with severe grass pollen allergic symptoms: a double-blind placebo-controlled study. Allergy 59: 498-504.

22. Scadding GW, Shamji MH, Jacobson MR, Lee DI, Wilson D, et al. (2010) Sublingual grass pollen immunotherapy is associated with increases in sublingual Foxp3-expressing cells and elevated allergen-specific immunoglobulin G4 immunoglobulin $A$ and serum inhibitory activity for immunoglobulin E-facilitated allergen binding to B cells. Clin Exp Allergy 40: 598-606.

23. Lima MT, Wilson D, Pitkin L, Roberts A, Nouri-Aria K, et al. (2002) Grass pollen sublingual immunotherapy for seasonal rhinoconjunctivitis: a randomized controlled trial. Clin Exp Allergy 32: 507-514.

24. Marcucci F, Sensi L, Incorvaia C, Dell'albani I, Di Cara G, et al. (2012) Specific $\mathrm{lgE}$ response to different grass pollen allergen components in children undergoing sublingual immunotherapy. Clin Mol Allergy 10: 7

25. Clavel R, Bousquet J, André C (1998) Clinical efficacy of sublingual-swallow immunotherapy: a double-blind, placebo-controlled trial of a standardized fivegrass-pollen extract in rhinitis. Allergy 53: 493-498.

26. Mösges R, Brüning H, Hessler HJ, Götz G, Knaussmann HG (2007) Sublingua immunotherapy in pollen-induced seasonal rhinitis and conjunctivitis: a randomized controlled trial. Acta Dermatovenerol Alp Panonica Adriat 16: 143 148.

27. Pfaar O, Klimek L (2008) Efficacy and safety of specific immunotherapy with a high-dose sublingual grass pollen preparation: a double-blind, placebocontrolled trial. Ann Allergy Asthma Immunol 100: 256-263.

28. Rossi RE, Monasterolo G, Coco G, Silvestro L, Operti D (2007) Evaluation of serum IgG4 antibodies specific to grass pollen allergen components in the follow up of allergic patients undergoing subcutaneous and sublingual immunotherapy. Vaccine 25: 957-964

29. Savolainen J, Jacobsen L, Valovirta E (2006) Sublingual immunotherapy in children modulates allergen-induced in vitro expression of cytokine mRNA in PBMC. Allergy 61: 1184-1190.

30. Piconi S, Trabattoni D, Rainone V, Borgonovo L, Passerini S, et al. (2010) Immunological effects of sublingual immunotherapy: clinical efficacy is associated with modulation of programmed cell death ligand 1, IL-10, and IgG4 J Immunol 185: 7723-7730.

31. Ciprandi G, De Amici M, Tosca M, Marseglia G (2010) Serum transforming growth factor-beta levels depend on allergen exposure in allergic rhinitis. In Arch Allergy Immunol 152: 66-70.

32. Moingeon $P$, Mascarell $L$ (2012) Induction of tolerance via the sublingual route: mechanisms and applications. Clin Dev Immunol 2012: 623474

33. Shamji MH, James LK, Durham SR (2011) Serum immunologic markers for monitoring allergen-specific immunotherapy. Immunol Allergy Clin North Am 31: $311-323$ 